\title{
Absolute densities of long lived species in an ionized physical vapor deposition copper-argon plasma
}

\author{
Y. Andrew, ${ }^{\text {a) }}$ I. Abraham, J. H. Booske, Z. C. Lu, and A. E. Wendt \\ Center for Plasma Aided Manufacturing, University of Wisconsin-Madison, 1410 Engineering Drive, \\ Madison, Wisconsin 53706
}

(Received 27 March 2000; accepted for publication 22 June 2000)

\begin{abstract}
Optical absorption spectroscopy has been used to measure absolute, average gas phase densities of neutral copper, ground and metastable states, and neutral argon, metastable and resonance states, in an ionized physical vapor deposition plasma. Spectroscopic measurements were carried with a xenon arc lamp as a high intensity, continuum light source, and an optical multichannel detector. Copper radiative transitions in the wavelength range of 324.8-510.6 nm and argon radiative transitions in the 706.7-811.5 nm range were employed. The curve of growth method has been used to calculate the absolute line average densities from fractional absorption data. For a copper-argon plasma of neutral pressure 30 and 10 mTorr copper metastable state densities were found to lie in the range of $10^{10}-10^{12} \mathrm{~cm}^{-3}$. Comparison of these densities with neutral copper densities derived from independent measurements of neutral copper flux at the substrate indicate gas phase temperatures greater than $1500 \mathrm{~K}$ under certain experimental conditions. These values of inferred temperatures indicate the copper metastable state density to be significant in comparison with neutral copper ground state densities at 10 and 30 mTorr with radio frequency heating power of 1 $\mathrm{kW}$. The concentrations of argon $4 s$ sublevels of the first excited state were found to be in the range of $4.5 \times 10^{8}-1.5 \times 10^{11} \mathrm{~cm}^{-3}$ for the experimental conditions studied. The ordering of the relative densities of the argon $4 s$ sublevels and the variation of the lumped first excited state with experimental parameters are discussed. (C) 2000 American Institute of Physics.
\end{abstract}

[S0021-8979(00)02819-X]

\section{INTRODUCTION}

Ionized physical vapor deposition (IPVD) discharges are currently used to deposit barrier layers such as titanium nitride, and thin metal films such as copper, as seed layers in high aspect ratio features for integrated circuit fabrication. In IPVD sputtered atoms are ionized in-flight as they traverse a high density plasma before depositing on the substrate. The depositing, ionized metal flux can be collimated by the electric field at the biased substrate. IPVD offers the advantage of improved conformality due to the enhanced directionality of the depositing material over conventional physical vapor deposition techniques. Recent work has focused on the development of codes to improve our understanding of the physics of IPVD discharges. ${ }^{1,2}$ Crucial to such efforts are measurements of absolute densities of long lived gas phase species. For example, the metastable argon states, $1 s_{5}$ and $1 s_{3}$ (Paschen notation), and resonance levels, $1 s_{4}$ and $1 s_{2}$, are important to the discharge physics since their long lifetimes have a significant effect on the power and ionization balance of IPVD plasmas.

In this article we report absolute, average gas phase densities of copper (ground and metastable states) and argon (metastable and resonance states). These densities have been derived from experimental measurements of fractional optical absorption values using the curve of growth method. The dependencies of the gas phase concentrations on variable experimental parameters are also discussed. Also, by compar-

${ }^{a)}$ Electronic mail: yandrew@engr.wisc.edu ing copper fluxes measured directly with those computed from spectroscopically determined gas phase concentrations, useful values of the gas phase copper temperature have been inferred.

\section{EXPERIMENT}

Figure 1 shows a schematic of the IPVD experimental setup. All measurements were performed in an aluminum vacuum chamber, $45 \mathrm{~cm}$ in diameter and $52 \mathrm{~cm}$ in height. A base pressure of roughly $1 \times 10^{-6}$ Torr and working argon gas pressures of 10,30, and 50 mTorr were used. Copper was introduced into the discharge with a dc magnetron sputter gun. The surface of the $15-\mathrm{cm}$-diameter copper target was a distance of $10 \mathrm{~cm}$ from the wafer chuck. The dc magnetron sputter power used in this study ranged from 0 to $200 \mathrm{~W}$. An inductively coupled argon plasma was used to ionize the sputtered copper atoms. This secondary plasma was generated with a single-turn internal copper coil, $36 \mathrm{~cm}$ in diameter with a $0.64 \mathrm{~cm}$ cross-section diameter, also depicted in Fig. 1. The $13.56 \mathrm{MHz}$ rf power was varied from $50 \mathrm{~W}$ to 2 $\mathrm{kW}$ for the experimental investigation, yielding typical electron densities of $\sim 10^{12} \mathrm{~cm}^{-3}$ and electron temperatures of $\sim 2 \mathrm{eV}$ in the vicinity of the $\mathrm{rf}$ coil. ${ }^{3}$ The rf power to the coil was coupled using an automatching network, to keep the reflected power below $10 \%$ of the incident power.

Figure 2 is a schematic of the spectroscopic setup. A stable xenon arc lamp (Hammamatsu Photonics Super Quiet) was used as a continuum source. The continuum beam has a diameter of $2.5 \mathrm{~cm}$ and was passed through the IPVD cham- 


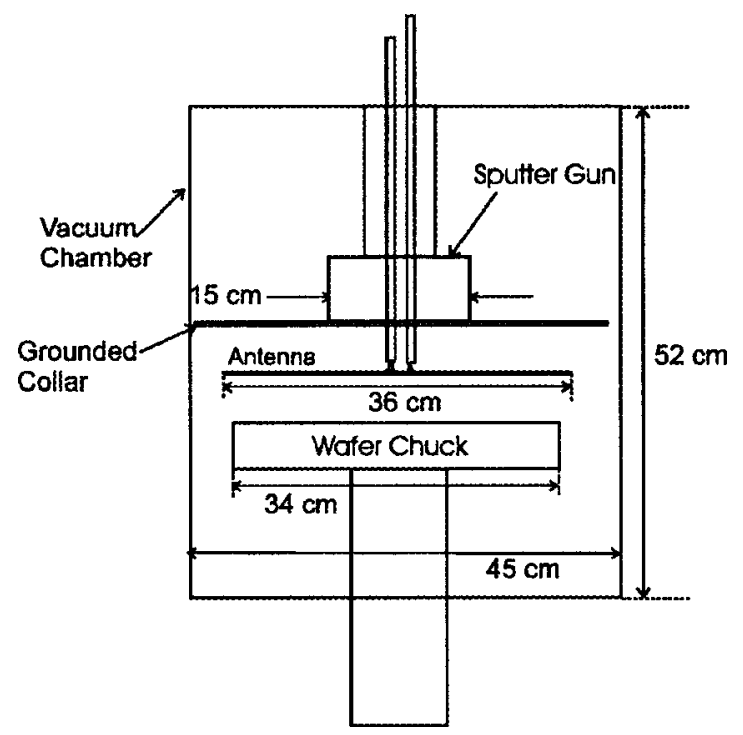

FIG. 1. Cross-sectional schematic diagram of vacuum chamber showing location of main components.

ber directly above the substrate stage, over the window-towindow path length of $46 \mathrm{~cm}$. A Jarrel Ash spectrometer with a focal length of $50 \mathrm{~cm}$ was used to detect radiation after transmission through the IPVD plasma. The spectrometer is equipped with an echelle grating of dimensions, $93 \mathrm{~mm} \times 55 \mathrm{~mm}$, with a groove density of 316 grooves $/ \mathrm{mm}$ and $63^{\circ}$ blaze. A small low-resolution grating monochromator (ISA Model H10) with a $10 \mathrm{~cm}$ focal length was used as a premonochromator with a spectral range of $5 \mathrm{~nm}$.

The Jarrel Ash spectrometer is equipped with a multichannel detector consisting of a 1024-pixel Si photodiode array (PDA). To suppress noise contribution from thermally generated charge carriers, the detector enclosure is evacuated (to $<150$ mTorr) and the PDA chip is cooled to as low as $-25^{\circ} \mathrm{C}$ with a built in Peltier cooler. An optical multichannel analyzer (OMA) data acquisition system is used to record the signal (intensity counts), digitizing the analog signals. The resolution of the detection system is $0.01 \mathrm{~nm} / \mathrm{pixel}$ and small fractional absorptions of as low as $10^{-2}$ have been detected with it.

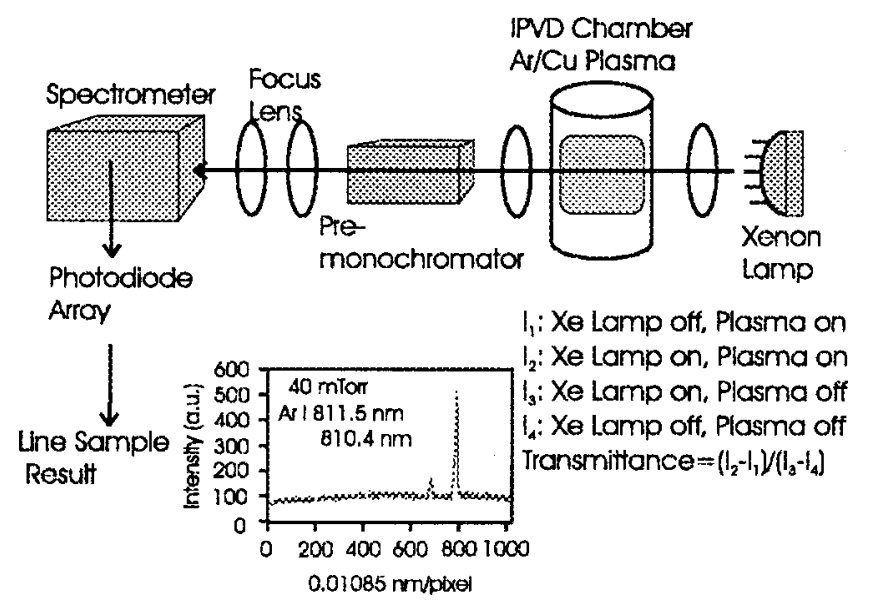

FIG. 2. Schematic of optical absorption spectroscopy setup.

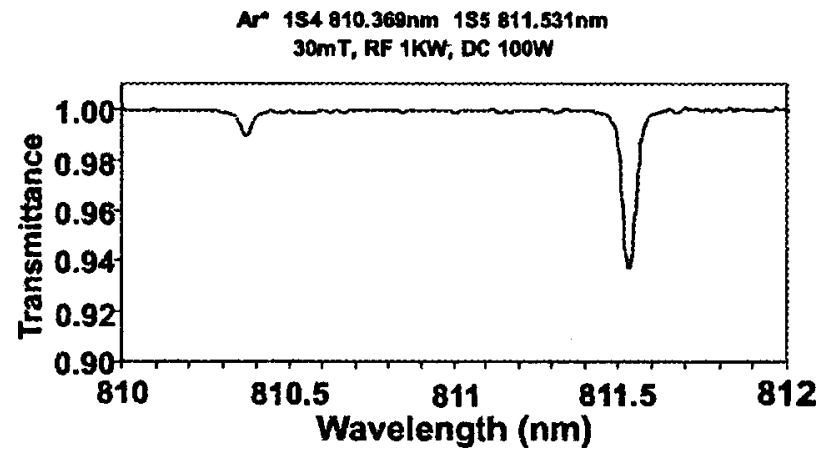

FIG. 3. Absorption spectrum recorded at a pressure of $30 \mathrm{mTorr}$, dc sputter power of $100 \mathrm{~W}$, and rf power of $1000 \mathrm{~W}$, for $\lambda=810.4$ and $811.5 \mathrm{~nm}$.

A digital subtraction technique previously described by Walmsley and Lawler ${ }^{4}$ was employed to measure the desired absorption spectra. The plasma emission signal must be comparable to, or less than, the signal from the xenon arc lamp for the digital subtraction to be practical. ${ }^{4}$ The basic procedure involves recording four spectra. The first spectrum, $I_{1}$, is taken when a screen blocks the arc lamp. Only plasma line emission is recorded. The second spectrum, $I_{2}$, is measured when the screen is removed, the superposition of the arc lamp and the plasma spectrum is measured. The third and fourth spectra are recorded with the plasma switched off. The third spectrum, $I_{3}$, is recorded with the removal of the screen, so only the lamplight reaches the detector. The fourth spectrum, $I_{4}$, is measured with the screen blocking the arc lamp, so only background light and thermally generated noise in the semiconductor detector is recorded. This protocol is summarized in Fig. 2. Once all four spectra have been recorded they are combined to yield a final absorption spectrum. The profile of transmittance, $T$, versus wavelength, $\lambda$, is obtained by subtracting pixel by pixel, $I_{1}$ and $I_{2}$, and dividing this difference by the dark count corrected spectrum of the xenon lamp continuum, $I_{3}$ minus $I_{4}$,

$$
T(\lambda)=\frac{I_{2}-I_{1}}{I_{3}-I_{4}} .
$$

This last step eliminates the pixel-to-pixel variations in the detection array and from the xenon lamp. It should be noted that the integration time for taking each spectrum must precisely match if one wants to subtract two spectra and detect small fractional absorption. An example of a final absorption spectrum is given in Fig. 3.

Neutral copper deposition rates were measured using a water-cooled, biased quartz crystal microbalance, which was placed directly on top of the wafer chuck. The crystal surface exposed to deposition is coated with a thin gold or silver film upon which the copper film is deposited. The quartz crystal acts as a piezoelectric transducer in an oscillator circuit, in which the resonant frequency is dependent on the mass load on the quartz crystal. In the instrument used for these measurements the front surface can be biased relative to the plasma potential. By applying a bias voltage above the plasma potential, ions are repelled and deposition due to neutrals only can be monitored. A magnetic field is used to protect the crystal from drawing a large electron saturation 
current when biased above the plasma potential. A more detailed description of this diagnostic is given in Ref. 5. Radial profiles of the neutral copper deposition rate were measured across the $46 \mathrm{~cm}$ optical absorption spectroscopy (OAS) line of sight. Experimental conditions similar to those set for the OAS data were used. Values of average total deposition rate were then calculated and used to infer average values of neutral copper density for comparison with the values inferred from OAS measurements. These comparisons have been carried across a range of assumed temperatures, which has also allowed values of neutral copper temperature to be estimated. This is discussed further in Sec. IV A.

\section{DENSITY CALCULATIONS FOR OPTICAL ABSORPTION MEASUREMENTS}

Densities can be obtained from fractional absorption data by measuring one of three quantities: the peak fractional absorption, the area under the absorbance $[-\log ($ transmittance $)]$ of a line, or the area under the fractional absorption of a given spectral line. The peak fractional absorption is the easiest to measure, but produces erroneously low density results if the spectral linewidth is significantly narrower than the instrumental resolution. The most general method uses the area under the fractional absorption to compute the equivalent width, which is conserved regardless of instrumental linewidth. The equivalent width is then used with the curve of growth method ${ }^{6}$ to obtain accurate density results even for strongly absorbed narrow lines, which appear to have small fractional absorptions because of the large difference between the spectral $(0.005 \mathrm{~nm})$ and instrumental $(0.01 \mathrm{~nm})$ linewidths. The absorbance method is also independent of instrumental resolution, but underestimates the density for strongly absorbing spectral lines. ${ }^{7}$

The density of absorbing species is related to the equivalent width, $W$, following the treatment of Penner, ${ }^{8}$ according to

$$
W \equiv \int_{\text {line }} d v\left[1-\frac{I(\nu)}{I_{0}}\right]=\int_{\text {line }} d \nu\left[1-e^{-P\left(v-v_{0}\right) X}\right],
$$

where $P$ is the spectral absorption coefficient $\left(\mathrm{m}^{-1} \mathrm{~atm}^{-1}\right), X$ is the optical density ( $\mathrm{m}$ atm), and

$$
P\left(v-v_{0}\right)=P^{\prime} f\left(v-v_{0}\right) .
$$

In Eq. (3), $\nu_{0}$ is the center frequency of the absorption line, $f\left(\nu-\nu_{0}\right)$ is the dimensionless line shape function, and

$$
P^{\prime}=\frac{S_{\text {line }}}{b_{D}} \sqrt{\frac{\ln 2}{\pi}}
$$

where $S_{\text {line }}$ is the line strength $\left(\mathrm{m}^{-1} \mathrm{~s}^{-1} \mathrm{~atm}^{-1}\right)$, and $b_{D}$ is the Doppler half-width at half maximum (HWHM) (Hz).

The line strength can be expressed as a function of the Einstein coefficient for spontaneous emission, $A_{u \rightarrow 1}$, as,

$$
S_{\text {line }}=\frac{c^{2}}{8 \pi v^{2}} \frac{N_{l}}{p} A_{u \rightarrow 1} \frac{g_{u}}{g_{1}},
$$

where $c$ is the speed of light $\left(\mathrm{m} \mathrm{s}^{-1}\right), \nu$ is the transition (line) frequency $(\mathrm{Hz}),\left(N_{l} / p\right)$ is the gas density (molecules $\left.\mathrm{m}^{-3} \mathrm{~atm}^{-1}\right)$ at standard temperature and pressure $\left(0^{\circ} \mathrm{C}\right.$,
$1 \mathrm{~atm}), A_{u \rightarrow 1}$ is the Einstein coefficient for spontaneous emission $\left(s^{-1}\right)$, and $g_{u}$ and $g_{l}$ are the upper and lower state degeneracies, respectively (dimensionless).

The line shape produced by independent homogeneous (Lorentzian) and inhomogeneous (Gaussian) broadening mechanisms, called a Voigt profile, results in a spectral absorption coefficient $P$ of the form,

$$
P\left(v-v_{0}\right)=\frac{P^{\prime} a}{\pi} \int_{-\infty}^{+\infty} \frac{e^{-y^{2}} d y}{a^{2}+(\xi-y)^{2}},
$$

where,

$$
\begin{aligned}
& a=\frac{b_{L}}{b_{D}} \sqrt{\ln 2}, \\
& \xi=\frac{v-v_{0}}{b_{D}} \sqrt{\ln 2}, \\
& y=\frac{v^{\prime}-v_{0}}{b_{D}} \sqrt{\ln 2},
\end{aligned}
$$

$b_{L}$ is the Lorentzian linewidth (HWHM) $(\mathrm{Hz}), b_{D}$ is the Doppler linewidth (HWHM) (Hz), $\nu$ is the frequency at which $P\left(\nu-\nu_{0}\right)$ is evaluated $(\mathrm{Hz}), \nu_{0}$ is the absorption line center frequency $(\mathrm{Hz})$, and $\nu^{\prime}$ is the frequency corresponding to Doppler velocity component $(\mathrm{Hz})$.

The $a$ value, the ratio between the Lorentzian and Doppler halfwidths, is a measure of the importance of collisional broadening for the particular pressure of interest. An $a$ value of zero represents a purely Doppler broadened profile. The $a$ values for our measurements varied from 0.005 to 0.01 for ground state copper, depending on pressure and temperature, and 0.002 to 0.023 for the argon lines, with the important exception of the $750.384 \mathrm{~nm}$ argon line, whose $a$ value was in the range of $0.32-0.66$, due to the short lived (radiative) lower state.

The integral on the right-hand side of Eq. (6), called the Voigt integral, is well known in mathematics. It must be evaluated numerically in order to obtain solutions to Eq. (2) for particular equivalent widths and optical densities. The solutions of Eq. (2) for increasing absorption intensity for a particular $a$ value form a curve, called a "curve of growth.", 6 A table of equivalent widths was obtained by Jansson and Korb. ${ }^{9,10}$ We extended the range of their results by writing a Mathematica ${ }^{\circledR}$ program, which used the algorithm of Lether and Wenston ${ }^{11}$ to numerically solve the Voigt integral. The species density for a given equivalent width at any $a$ value was then obtained using this program. Representative curves of growth, for increasing $a$ values, are usually plotted on logarithmic scales as shown in Fig. 4, where the symbols indicate the values obtained from the table of Jansson and Korb. ${ }^{9,10}$ The curve for the lowest $a$ value shown in Fig. 4 is virtually identical to that for a pure Doppler profile. All the curves start out the same at low equivalent widths, but begin to diverge significantly as the nonlinear relationship shown in Eq. (2) between absorption and density begins to be more pronounced.

In the linear part of the curve of growth, called the optically thin region, the argument of the exponential in Eq. (2) is small and the approximation 


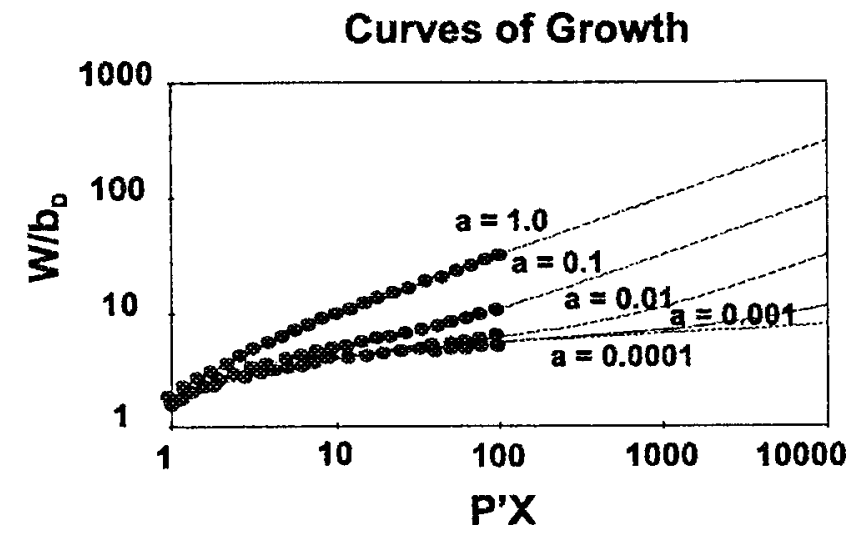

FIG. 4. Curves of growth for a range of $a$ values.

$$
e^{-x} \cong 1-x
$$

can be used. Therefore,

$$
W=\int_{\text {line }} d v\left[1-\frac{I(v)}{I_{0}}\right] \cong \int_{\text {line }} d v\left[P\left(v-v_{0}\right) X\right]=S_{\text {line }} X
$$

because,

$$
\frac{1}{b_{D}} \sqrt{\frac{\ln 2}{\pi}} \int_{-\infty}^{+\infty} d v f\left(v-v_{0}\right)=1
$$

A useful property of Eq. (11) is that there is no temperature dependence remaining in the final density result. It is important to remember, however, that Eq. (11) only applies when the $W / b_{D}$ ratio is less than about one, in the linear region of the curve of growth, not included in Fig. 4. The full form of Eq. (2) must be evaluated numerically in order to obtain accurate number densities beyond that point, due to the nonlinear relationship between density and absorption intensity, shown in Fig. 4.

\section{A. Hyperfine structure of ground state copper absorption line}

The spectroscopic absorption line used to obtain densities of ground state copper atoms, called the $D_{2}$ line at $324.7540 \mathrm{~nm}$, is not a single line. It is actually composed of a hyperfine structure due to the magnetic interaction between the nuclear spin and the spin of the orbital electrons. ${ }^{12}$ The resulting lines are separated by more than a Doppler width, but are resolved only in very high resolution experiments. ${ }^{13}$ In addition, the isotope effect for copper $\left[{ }_{29} \mathrm{Cu}^{63}(69.09 \%)\right.$ and $\left.{ }_{29} \mathrm{Cu}^{65}(30.91 \%)\right]$ doubles the number of lines. Because the hyperfine lines are separated in frequency by more than a Doppler width, the multiplet structure must be explicitly treated in our curve of growth method in order to obtain accurate ground state copper atom densities, even though the hyperfine structure is not resolved at our instrumental resolution. The application of the curve of growth method to multiple line components is detailed in Appendix A. Due to the increased computational complexity required to treat the hyperfine structure, our results are reported at three selected temperatures within an estimated gas phase temperature range, 350,500 , and $1500 \mathrm{~K}$. Clearly, measurements of the

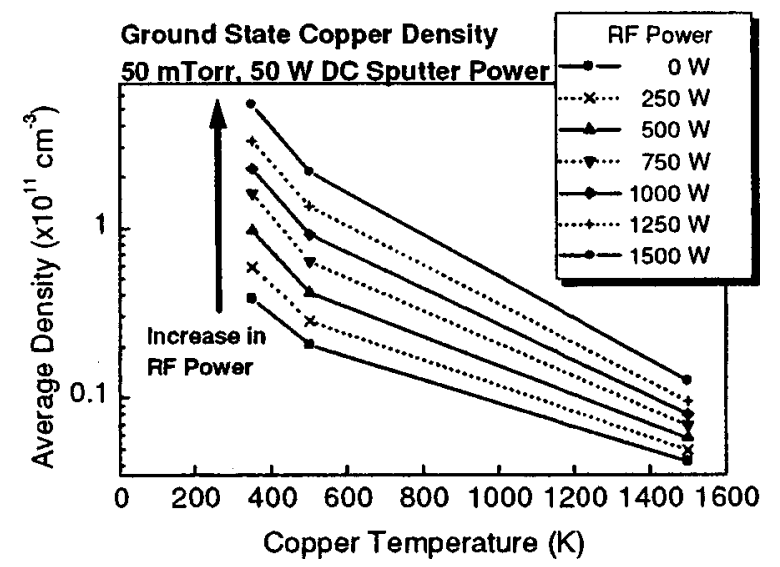

FIG. 5. Ground state, neutral copper densities plotted as a function of assumed copper temperature for argon pressure, 50 mTorr, $50 \mathrm{~W}$ dc sputter power, and variable radio frequency power, rf.

gas phase species temperature are important to the derivation of accurate densities. In the absence of direct temperature measurements, an attempt has been made to infer neutral copper temperatures by comparing two independent measurements of copper density across the range of assumed temperature.

\section{RESULTS}

\section{A. Copper}

Figures 5 and 6 show the values of ground state, neutral copper density derived from OAS measurements. These results have been plotted as a function of assumed copper temperature at pressures of 50 (Fig. 5), 30, and 10 mTorr (Fig. 6 ). For the $50 \mathrm{mTorr}$ case, the rf inductively coupled plasma (ICP) power was varied from 0 to $1500 \mathrm{~W}$ in $250 \mathrm{~W}$ increments, while the dc sputter power was kept constant at $50 \mathrm{~W}$. For the 30 and $10 \mathrm{mT}$ Torr cases, the rf ICP power was set at 1000 and $2000 \mathrm{~W}$, while the sputter power was set at 100 and $200 \mathrm{~W}$. It may be incorrect to assume a single copper temperature under varying conditions of argon pressure, $\mathrm{rf}$ ICP power or dc sputter power. Therefore, assumed copper temperature was chosen as the $x$-axis variable. The error

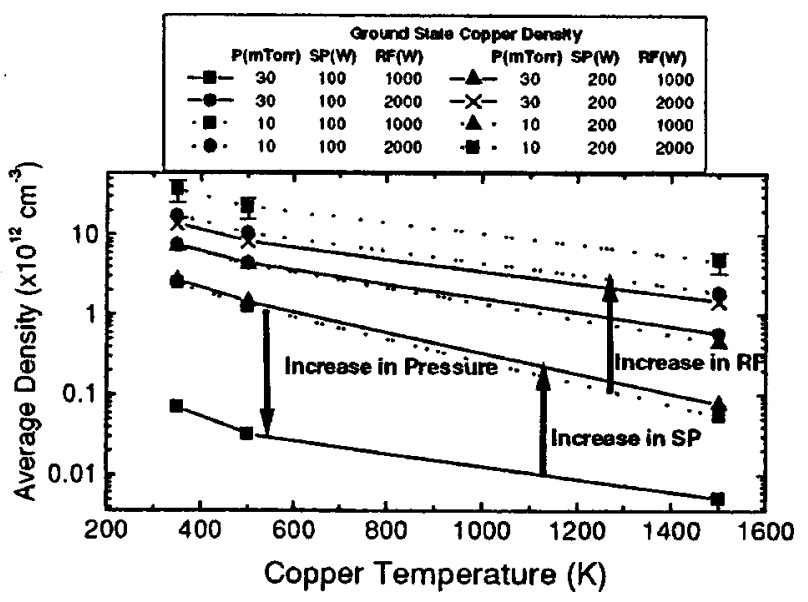

FIG. 6. Neutral copper, ground state densities plotted as a function of assumed copper temperature for variable values of argon pressure, dc sputter power, and radio frequency power, rf. 
TABLE I. Comparison of ground and metastable state copper densities.

\begin{tabular}{|c|c|c|c|c|c|c|}
\hline $\begin{array}{c}\text { Ar } \\
\text { pressure } \\
\text { (mTorr) }\end{array}$ & $\begin{array}{c}\mathrm{rf} \\
\text { power } \\
(\mathrm{W})\end{array}$ & $\begin{array}{c}\text { Sputter } \\
\text { power } \\
\text { (W) }\end{array}$ & $\begin{array}{l}\text { Ground } \\
\text { state } \mathrm{Cu} \\
\text { density } \\
\left(\mathrm{cm}^{-3}\right) \\
(@ 350 \mathrm{~K})\end{array}$ & $\begin{array}{c}\text { Ground } \\
\text { state } \mathrm{Cu} \\
\text { density } \\
\left(\mathrm{cm}^{-3}\right) \\
(@ 500 \mathrm{~K})\end{array}$ & $\begin{array}{c}\text { Ground } \\
\text { state } \mathrm{Cu} \\
\text { density } \\
\left(\mathrm{cm}^{-3}\right) \\
(@ 1500 \mathrm{~K})\end{array}$ & $\begin{array}{c}\text { Metastable } \\
\text { state } \mathrm{Cu} \\
\text { density } \\
\left(\mathrm{cm}^{-3}\right)\end{array}$ \\
\hline \multirow{2}{*}{30} & 1000 & $\begin{array}{r}0 \\
100 \\
200\end{array}$ & $\begin{array}{l}2.50 \times 10^{9} \\
6.96 \times 10^{10} \\
2.72 \times 10^{12}\end{array}$ & $\begin{array}{l}3.23 \times 10^{10} \\
1.44 \times 10^{12}\end{array}$ & $\begin{array}{c}5.20 \times 10^{9} \\
7.8 \times 10^{10}\end{array}$ & $\begin{array}{l}2.37 \times 10^{10} \\
5.79 \times 10^{10} \\
8.20 \times 10^{10}\end{array}$ \\
\hline & 2000 & $\begin{array}{r}0 \\
100 \\
200\end{array}$ & $\begin{array}{l}7.56 \times 10^{12} \\
1.36 \times 10^{13}\end{array}$ & $\begin{array}{r}4.5 \times 10^{12} \\
8.29 \times 10^{12}\end{array}$ & $\begin{array}{r}5.8 \times 10^{11} \\
1.47 \times 10^{12}\end{array}$ & $\begin{array}{r}3.0 \times 10^{10} \\
4.77 \times 10^{10} \\
7.48 \times 10^{10}\end{array}$ \\
\hline \multirow[b]{2}{*}{10} & 1000 & $\begin{array}{r}0 \\
100 \\
200\end{array}$ & $\begin{array}{l}2.47 \times 10^{12} \\
7.17 \times 10^{12}\end{array}$ & $\begin{array}{l}1.25 \times 10^{12} \\
4.20 \times 10^{12}\end{array}$ & $\begin{array}{l}5.44 \times 10^{10} \\
4.48 \times 10^{11}\end{array}$ & $\begin{array}{c}9.73 \times 10^{9} \\
2.01 \times 10^{10} \\
2.87 \times 10^{10}\end{array}$ \\
\hline & 2000 & $\begin{array}{r}0 \\
100 \\
200\end{array}$ & $\begin{array}{l}1.72 \times 10^{13} \\
3.63 \times 10^{13}\end{array}$ & $\begin{array}{l}1.05 \times 10^{13} \\
2.24 \times 10^{13}\end{array}$ & $\begin{array}{l}1.90 \times 10^{12} \\
4.75 \times 10^{12}\end{array}$ & $\begin{array}{l}1.50 \times 10^{10} \\
2.12 \times 10^{10} \\
2.90 \times 10^{10}\end{array}$ \\
\hline
\end{tabular}

from the repeatability of the spectroscopic measurements gives a $\pm 21 \%$ uncertainty in the equivalent widths. A sensitivity analysis of the calculated density to a $\pm 10 \%$ uncertainty in the equivalent width, was carried out for the single case of 10 mTorr, $200 \mathrm{~W}$ dc sputter power, and $2000 \mathrm{~W}$ rf power. This led to a $\pm 30 \%$ error in the derived density and is shown as error bars for this particular case in Fig. 6 .

Figures 5 and 6 show the copper density to have a strong dependence on the assumed copper temperature. This dependence makes the evaluation of trends in ground state copper density with the variable experimental parameters, such as plasma power and neutral pressure, difficult without an independent measurement of the copper neutral temperature. However, at each assumed temperature the neutral copper, ground state density was found to increase with dc sputter power from 100 to $200 \mathrm{~W}$, by a factor of between 1.8 and 44, with the largest increase occurring at 30 mTorr and $1000 \mathrm{~W}$ rf power. At each assumed temperature, the neutral copper ground state density was also found to increase with rf power, from 0 to $1500 \mathrm{~W}$ in Fig. 5 and from 1000 to $2000 \mathrm{~W}$ in Fig. 6, by a factor between 5 and 140. This trend is most clearly seen in Fig. 5 and by an example indicated in Fig. 6. Finally, decreasing the neutral argon pressure from 30 to 10 mTorr led to an increase in neutral copper, ground state densities by a factor ranging from 2.6 to 39 . An example of this trend is also highlighted in Fig. 6.

The increase in neutral copper, ground state density with higher dc sputter power is expected to be the direct result of the associated increase in metal flux into the discharge. The increase in neutral copper concentrations at higher rf powers is thought to be a consequence of two possible factors. Denser plasmas and the more negative bias of the inductive coil associated with increased rf power leads to a higher coil sputter rate. Such a local increase in copper influx into the discharge could also cause rarefaction of the neutral argon gas in the vicinity of the coil. This effect could in turn allow more copper neutrals to reach the substrate rather than being scattered and redeposited on the sputter target and coil. Fi- nally, the observed decrease in neutral copper concentration with increasing argon pressure may be an effect of enhanced ionization. As the background neutral argon pressure increases, the copper atoms sputtered from the target have a greater likelihood of being thermalized and subsequently ionized. The result is an increased ionized metal flux fraction for a given metal flux from the target and hence a decrease in the neutral copper density. This explanation is supported by measurements of ionized metal flux fractions at the substrate. $^{14}$

Shown in Table I are the values of neutral copper, metastable, and ground state densities derived from OAS measurements at the three assumed temperatures. The metastable densities are independent of assumed copper temperature, since their absorption values correspond to the linear part of the curve of growth. The neutral copper, metastable state densities are found to increase with both dc sputter power and argon pressure and to show no strong dependence on $\mathrm{rf}$ power. Comparison of the metastable and ground state densities demonstrates the two species to be of the same order of magnitude under certain experimental conditions. However, the conditions for which this may be true are dependent upon the assumed copper temperature and specific examples are discussed at the end of this section.

The increase in neutral copper, metastable state densities with increasing sputter power is also expected to be a direct result of the associated higher metal flux into the discharge. The dependence of the copper metastable state concentration on rf power and argon pressure is thought to be less straightforward. For example, increased argon pressure results in increased thermalization of the sputtered copper atoms. This in turn allows electron impact excitation to and deexcitation from the copper metastable states to play a more important role. The greater number of neutral argon-neutral copper collisions as a result of increased argon pressure may also contribute to changes in neutral copper, metastable state density. The balance between the collisional population and depopulation processes of these states shifts with changing val- 


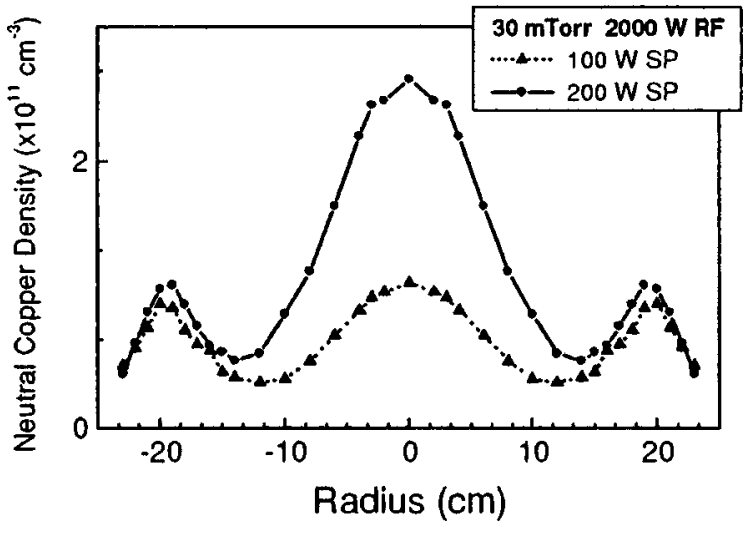

FIG. 7. An example of neutral copper density, radial profiles from QCM measurements of copper flux at an assumed copper temperatures of $1500 \mathrm{~K}$, 30 mTorr, $2000 \mathrm{~W}$ rf power, and variable dc sputter power.

ues of argon pressure, electron density, and electron temperature.

Total neutral copper densities (ground + metastable) derived from OAS measurements have been compared with values inferred from biased quartz crystal microbalance (QCM) measurements of neutral copper flux. The QCM measurements of deposition rate, $R_{\mathrm{dep}}\left(\mathrm{m} \mathrm{s}^{-1}\right)$, are related to a copper flux, $\Gamma_{\mathrm{Cu}}\left(\mathrm{Cu}\right.$ atoms $\left.\mathrm{m}^{-2} \mathrm{~s}^{-1}\right)$ by

$$
R_{\mathrm{dep}}=\frac{\Gamma_{\mathrm{Cu}}}{\rho_{\mathrm{Cu}}} \times \frac{64 \times 10^{-3}}{N_{A}},
$$

where $\rho_{\mathrm{Cu}}$ is the density of copper $\left(\mathrm{kg} \mathrm{m}^{-3}\right)$ and $N_{A}$ is the Avogadro constant. Since the quartz crystal microbalance is water cooled, a copper sticking coefficient of unity is assumed. The copper flux at the QCM, for an isotropic velocity distribution, is given by

$$
\Gamma_{\mathrm{Cu}}=\frac{1}{4} n \nu,
$$

where $n$ is the copper atom number density and $v$ is the velocity of the copper atoms depositing on the QCM. For a Maxwellian distribution, $v\left(\mathrm{~ms}^{-1}\right)$ is given by

$$
\nu=\left(\frac{8 k T}{\pi m_{\mathrm{Cu}}}\right)^{1 / 2},
$$

where $T$ is the assumed copper atom temperature $(\mathrm{K})$ and $m_{\mathrm{Cu}}$ is the mass of a copper atom $(\mathrm{kg})$. Substituting Eq. (14) into (13) and solving for $n\left(\mathrm{~m}^{-3}\right)$, gives an expression for the copper atom number density

$$
n=\frac{R_{\mathrm{dep}}}{\nu} \frac{\rho_{\mathrm{Cu}} N_{A}}{1.6 \times 10^{-2}} .
$$

Radial profile measurements of copper deposition rate were used to calculate an average copper atom number density along the optical absorption path length. Examples of the profiles are shown in Fig. 7 for assumed copper temperatures of $1500 \mathrm{~K}$, dc sputter powers of 100 and $200 \mathrm{~W}$, and a rf power of $2000 \mathrm{~W}$. The copper number densities calculated from the QCM measurements represent an upper limit since the sputtered copper species may also exist as clusters in the gas phase. Copper clusters cause the deposition rate to increase, resulting in lower real copper atom densities calculated from QCM measurements.

Without an independent measurement of gas phase, neutral copper temperature it is not possible to derive precise values of density from either the OAS or QCM measurements. Therefore, one of the most interesting results from the following comparison of independent measurements is that an approximate gas phase copper temperature can be inferred. In Fig. 8 the OAS and QCM values of neutral copper densities are compared at $30 \mathrm{mTorr}$, with the objective of finding a single point of agreement. Since the assumed temperature is not an independent variable, but an unknown input into the calculation of the concentrations from both the OAS and QCM data, this gives an estimate of the gas phase copper temperature. These two independent measurements show closer agreement at a rf power of $1000 \mathrm{~W}$ than at 2000 $\mathrm{W}$, however it is possible that the gas phase copper temperature lies outside the range considered. For the $100 \mathrm{~W}$ dc sputter power and $1000 \mathrm{~W}$ rf power case, agreement to within a factor of 1.5 is observed at all assumed temperatures. At $200 \mathrm{~W}$ dc sputter power and $1000 \mathrm{~W}$ rf power the two curves show very close values at $\sim 1500 \mathrm{~K}$.
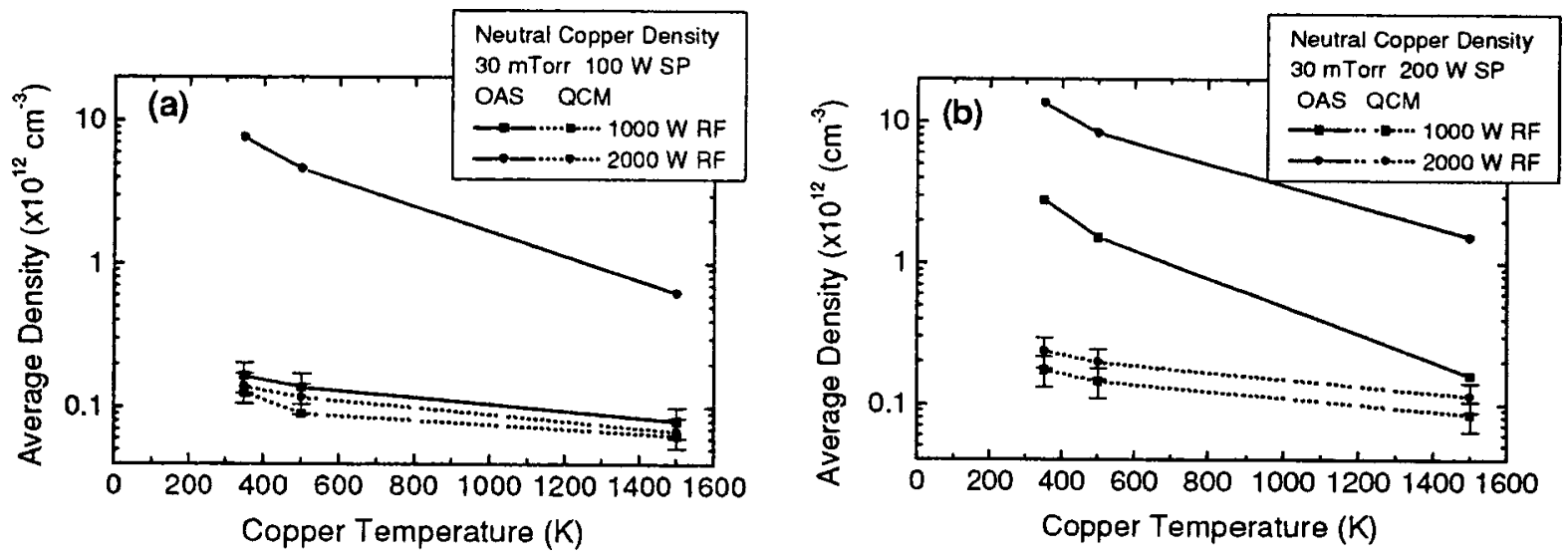

FIG. 8. Comparison of total copper density (ground+metastable) with copper density derived from QCM measurements of copper flux at $30 \mathrm{mTorr}$ for (a) $100 \mathrm{~W}$ sputter power and (b) $200 \mathrm{~W}$ sputter power. 


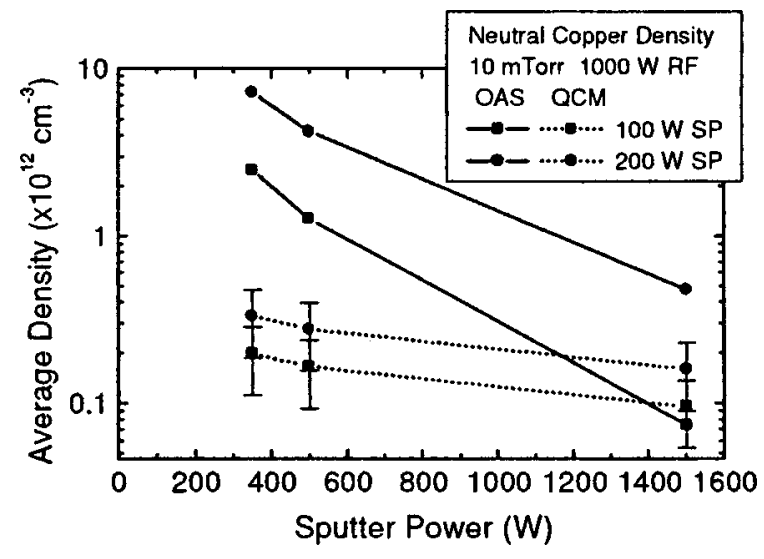

FIG. 9. Comparison of total copper density (ground+metastable) with copper density derived from QCM measurements of copper flux at 10 mTorr.

At a neutral argon pressure of 10 mTorr, data was only available with $1000 \mathrm{~W}$ rf power and is shown in Fig. 9. At 10 mTorr, $100 \mathrm{~W}$ sputter power the two curves cross at $\sim 1400$ $-1500 \mathrm{~K}$, while at $10 \mathrm{mTorr}, 200 \mathrm{~W}$ sputter power two measurements do not cross within the temperature range assumed.

The lack of agreement between the OAS and QCM curves, particularly for the 30 mTorr, $2000 \mathrm{~W}$ rf power cases, is mainly attributed to the temperature of thermalization being greater than $1500 \mathrm{~K}$. Several mechanisms may contribute to such high thermalization temperatures. With larger rf ICP powers, higher plasma potentials lead to increased ion acceleration to the walls and antenna. Through both charge exchange processes and neutral reflection these energetic ions may act as a significant source of neutral, background gas heating. Recent simulations by Lu et al. ${ }^{1}$ of an aluminum/argon IPVD system give maximum argon temperatures, and therefore thermalization temperatures, in the range of 700-1700 K. The argon temperatures in these simulations were also calculated to increase with rf ICP power as a result of charge exchange heating.

The inferred estimates of gas phase, neutral copper temperature allow a more accurate comparison of neutral copper ground state and metastable state concentrations to be carried out with the results in Table I. For example, for the two cases in which the curves cross, the average neutral copper temperature is $\sim 1500 \mathrm{~K}$ at $30 \mathrm{mTorr}, 200 \mathrm{~W}$ dc sputter power, and $1000 \mathrm{~W}$ rf power; and $\sim 1400-1500 \mathrm{~K}$ at $10 \mathrm{mTorr}, 200$ $\mathrm{W}$ sputter power, and $1000 \mathrm{~W}$ rf power. At $1500 \mathrm{~K}$ the copper metastable state density given in Table $\mathrm{I}$ is 8.20 $\times 10^{10} \mathrm{~cm}^{-3}$ at $30 \mathrm{mTorr}, 200 \mathrm{~W}$ sputter power, and $1000 \mathrm{~W}$ rf and the ground state copper density is $7.8 \times 10^{10} \mathrm{~cm}^{-3}$. Similarly, the copper metastable state density of 2.21 $\times 10^{10} \mathrm{~cm}^{-3}$ at $10 \mathrm{mTorr}, 100 \mathrm{~W}$ sputter power, and $1000 \mathrm{~W}$ rf power is comparable to the ground state copper density of $5.44 \times 10^{10} \mathrm{~cm}^{-3}$ at $1500 \mathrm{~K}$. Therefore the copper metastable state density is found to be comparable to the ground state density under certain operating conditions. This is an extremely important result for calculation of copper flux to the substrate, discharge ionization balance, and power balance.

\section{B. Argon}

The absolute concentrations of metastable state argon atoms are shown as a function of sputter power in Figs. 10 and 11. The argon metastable state densities were found to be in the range of $4.5 \times 10^{8}-1.5 \times 10^{11} \mathrm{~cm}^{-3}$ for the condi-
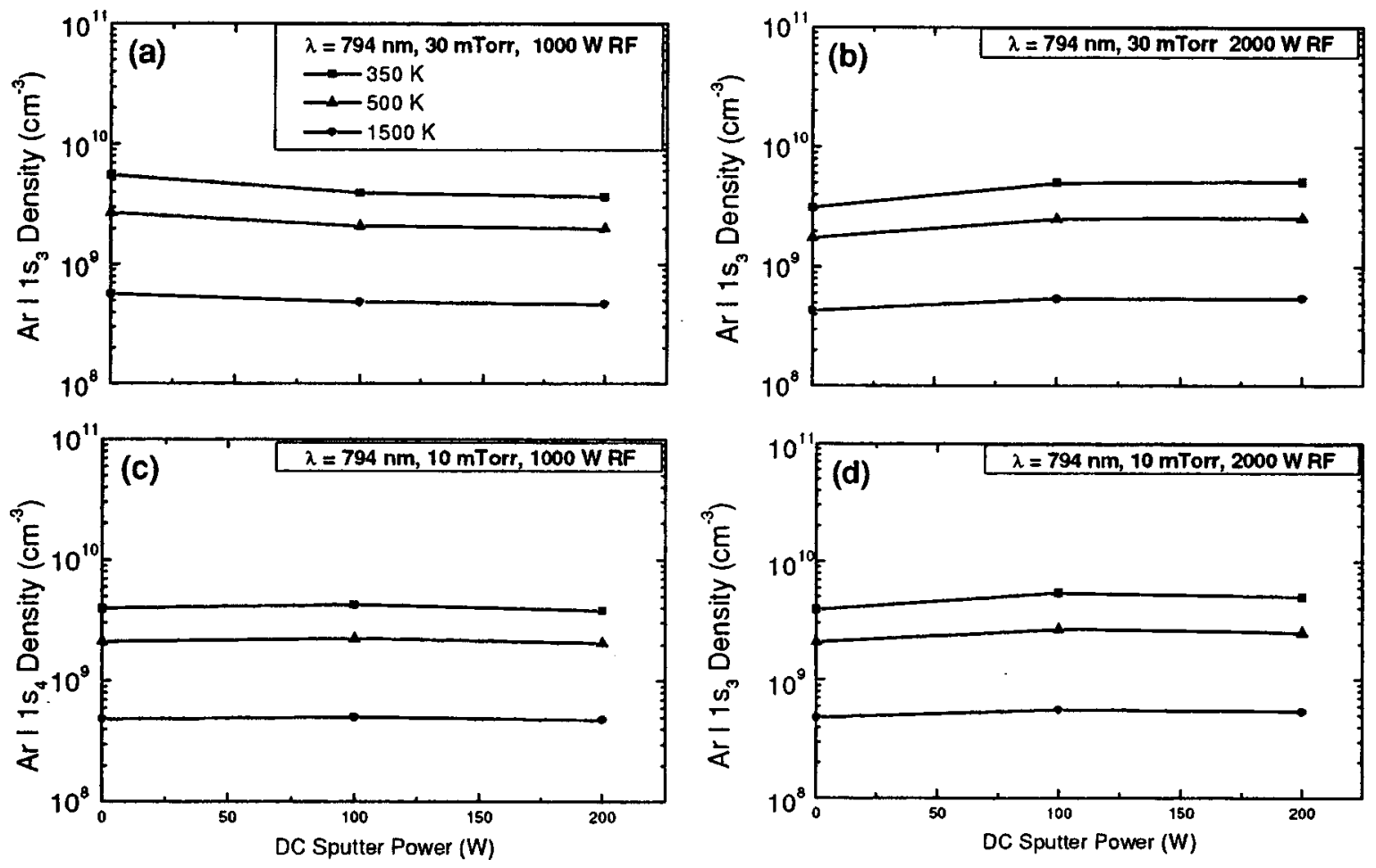

FIG. 10. Neutral Ar $1 s_{3}$ metastable state density plotted as a function of assumed Ar temperature for (a) $30 \mathrm{mTorr}$ and $1000 \mathrm{~W}$ rf, (b) 30 mTorr and $2000 \mathrm{~W}$ rf, (c) 10 mTorr and $1000 \mathrm{~W}$ rf, and (d) 10 mTorr and $2000 \mathrm{~W}$ rf. Densities were derived using Ar I line, $\lambda=794 \mathrm{~nm}$. 

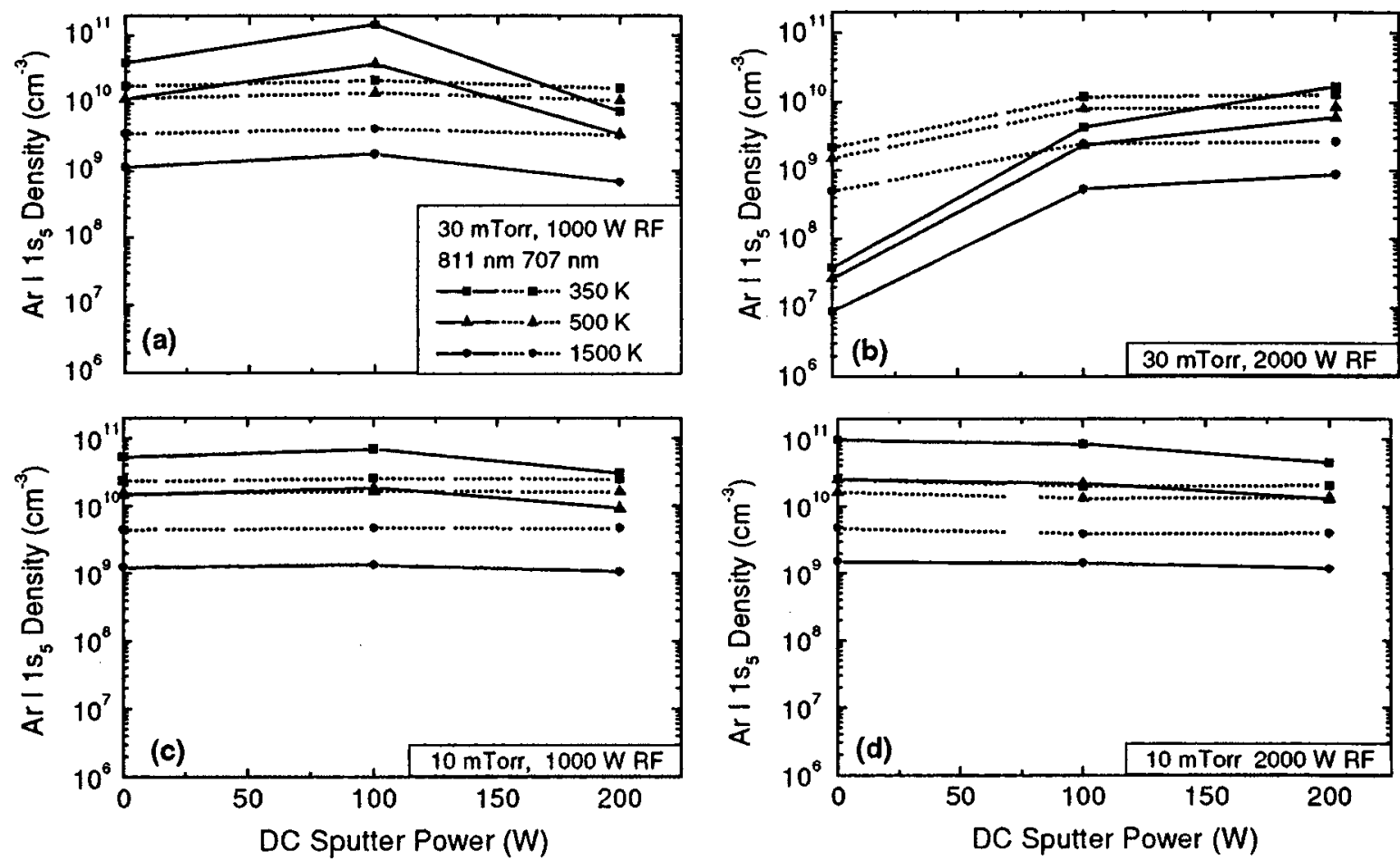

FIG. 11. Comparison of $\operatorname{Ar} I 1 s_{5}$ metastable densities derived from measured $\operatorname{Ar}$ I 811 and $707 \mathrm{~nm}$ fractional absorption line intensities as a function of sputter power for (a) $30 \mathrm{mTorr}, 1000 \mathrm{~W}$ rf, (b) $30 \mathrm{mTorr}, 2000 \mathrm{~W}$ rf, (c) $10 \mathrm{mTorr}, 1000 \mathrm{~W}$ rf, and (d) $10 \mathrm{mTorr}, 2000 \mathrm{~W}$ rf.

tions studied and temperatures assumed. The concentrations of the $1 s_{3}$ and $1 s_{5}$ metastable states do not show clear trends with changes in the variable experimental parameters. This observation may be attributed to the dependence of the population balance of the argon metastable states on the experimental conditions, as follows. Collisional excitation and deexcitation are the main methods of population and depopulation of metastable states. The experimental conditions under which one process dominates over the other determines the metastable state lifetimes and hence, densities. ${ }^{15}$ For example, under certain conditions an increase in electron density may lead to sufficient electron impact excitation to increase the metastable state densities. However, further increases in electron density with, for example, rf power, may result in increased collisional depopulation of the metastable states. The net effect could then be an observed decrease in metastable state population at higher rf power. Since this population balance shifts with changing experimental conditions, the metastable state densities may not show a clear trend with the experimental variables.

Figure 11 shows measurements of the same metastable state density, $1 s_{5}$, using two different spectroscopic lines (811 and $707 \mathrm{~nm}$ ), as a function of sputter power at 10 and 30 mTorr and at 1000 and $2000 \mathrm{~W}$ rf. General agreement is found to be in a range of factor of 1-6 for all cases apart from, $30 \mathrm{mTorr}$ and $2000 \mathrm{~W}$ rf power, when differences of up to a factor of 58 are observed. The raw data for the 811 $\mathrm{nm}$ line, in this particular case, has a very low signal-to-noise ratio. It is therefore expected that the lower calculated density has very large errors associated with it and has been discarded for purposes of this study.
Figures 12 and 13 show the argon resonant state densities, $1 s_{2}$ and $1 s_{4}$, also as a function of sputter power for various values of pressure and rf power. The resonant state densities do not show clear trends with changes in any of the variable parameters. Once again this is expected to be a result of the variation of the population balance of these states under changing conditions. For the resonant states deexcitation by photon emission and population through radiation trapping are additional depopulation/population mechanisms. Figure 13 shows concentrations of the resonance state, $1 s_{4}$, measured with two different Ar I spectroscopic lines, 751 and $810 \mathrm{~nm}$. The derived densities agree to within a factor of 4 apart from the 30 mTorr, $2000 \mathrm{~W}$ rf case in which much larger differences of up to a factor of 32 are observed. The large difference for this single case is thought to be a result of the substantially higher optical thickness of the plasma at the $751 \mathrm{~nm}$ line, which results in larger errors in the densities derived from this line. A small variation in absorption intensity at high optical thickness results in a large variation in density. Therefore, the densities derived from the $751 \mathrm{~nm}$ line are not used in the comparison of the relative concentrations of the $4 s$ sublevels or in the calculation of a total concentration of the $4 s$ manifold.

In Fig. 14 the relative concentrations of the $1 s_{2}, 1 s_{3}$, $1 s_{4}$, and $1 s_{5}$ sublevels comprising the $4 s$ excited state of neutral argon, are plotted at an assumed temperature of 1500 $\mathrm{K}$ at 10 and 30 mTorr and 1000 and $2000 \mathrm{~W}$ rf. Densities for the $1 s_{5}$ metastable state were derived from the ArI $707 \mathrm{~nm}$ line absorption fraction, and for the $1 s_{4}$ resonant state from the $810 \mathrm{mn}$ line absorption fraction. The observed ordering of level concentrations at $10 \mathrm{mTorr}$ is $1 s_{5}, 1 s_{4}, 1 s_{2}$, and 

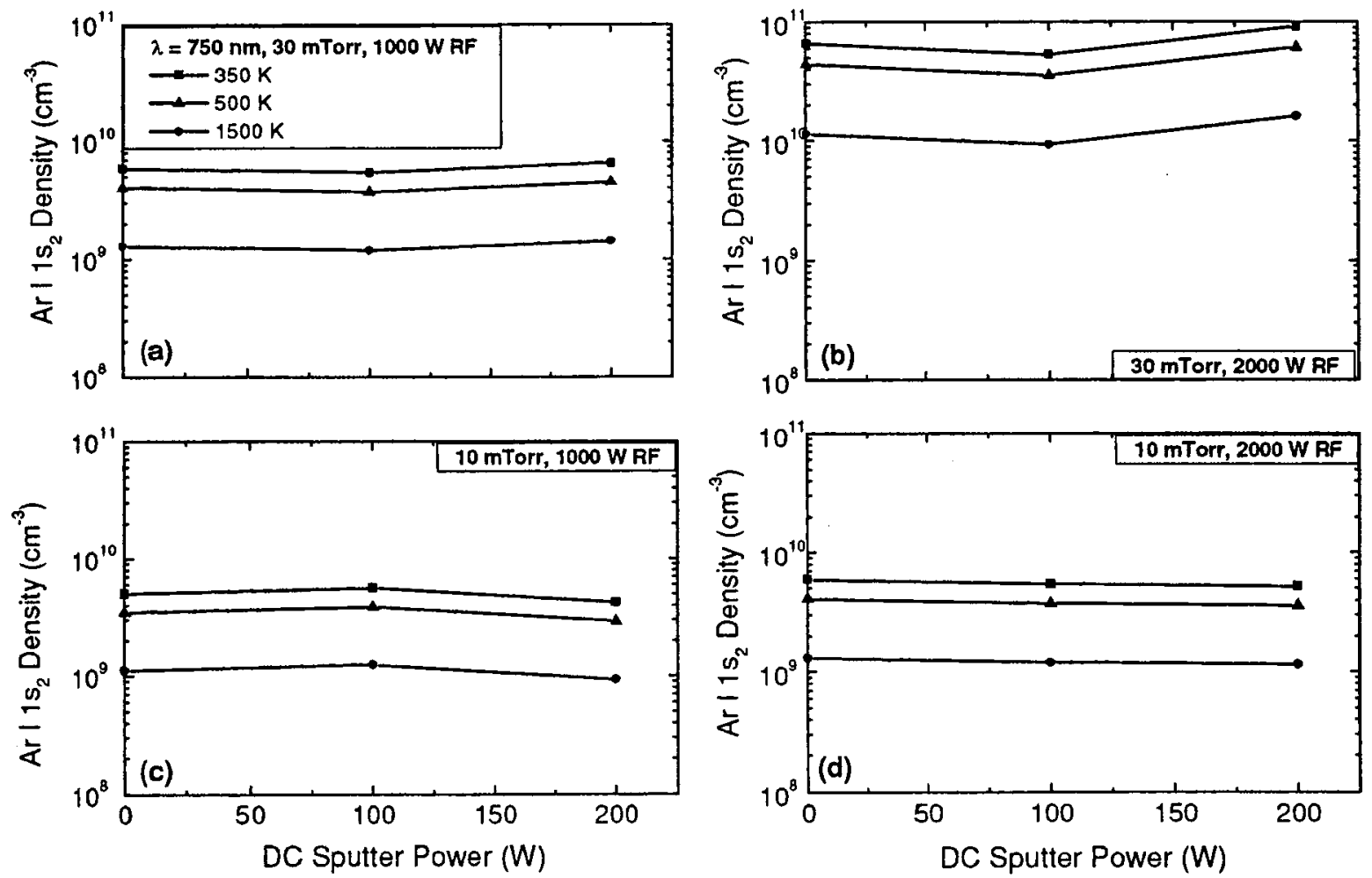

FIG. 12. Neutral Ar $1 s_{2}$ resonant state density plotted as a function of assumed Ar temperature for (a) 30 mTorr, $1000 \mathrm{~W}$ rf, (b) $30 \mathrm{mTorr}, 2000 \mathrm{~W}$ rf, (c) 10 mTorr, $1000 \mathrm{~W}$ rf, and (d) $10 \mathrm{mTorr}, 2000 \mathrm{~W}$ rf. Densities were derived using Ar I line, $\lambda=750 \mathrm{~nm}$.
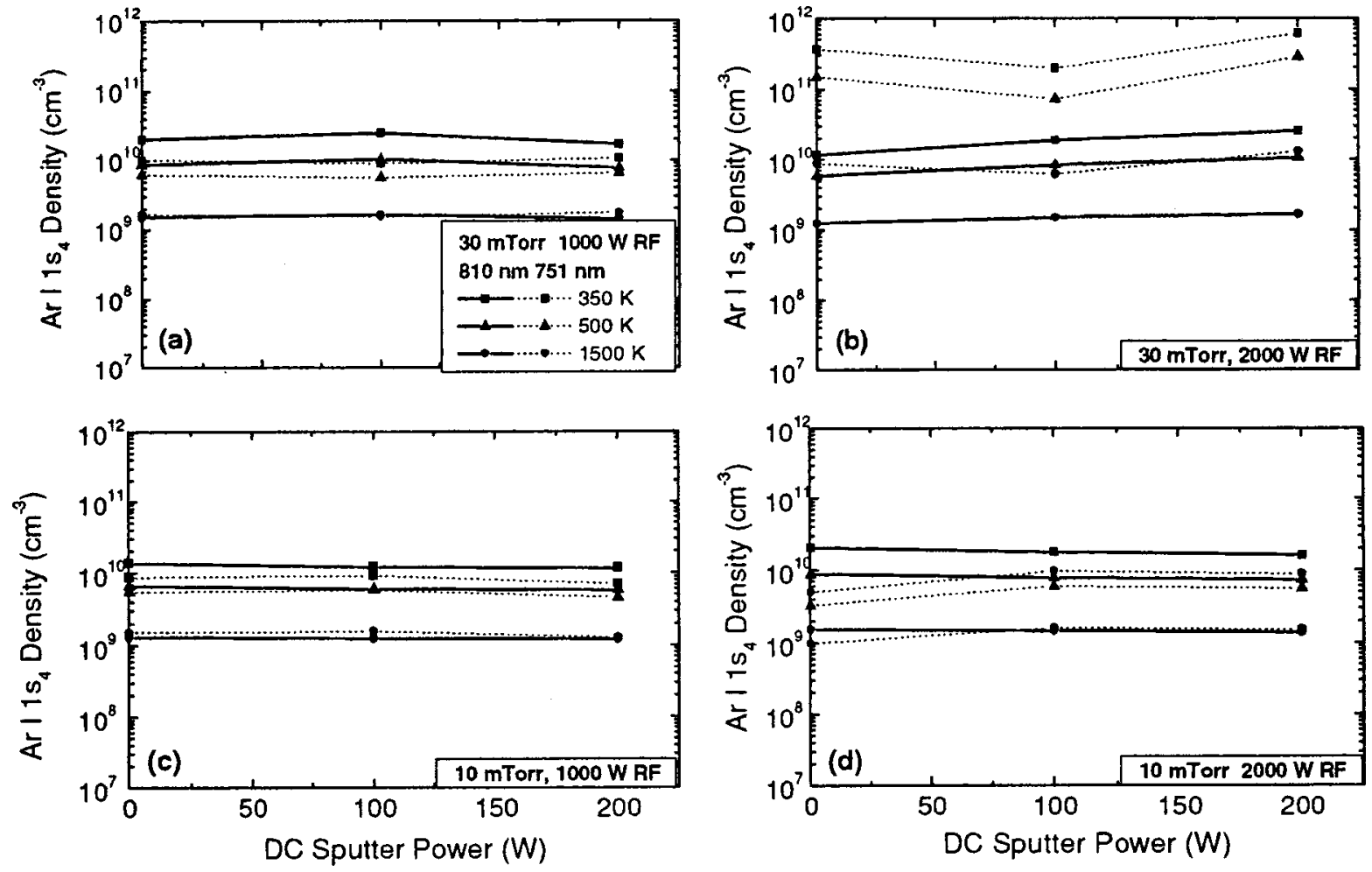

FIG. 13. Comparison of $\mathrm{Ar} \mathrm{I} 1 s_{4}$ metastable densities derived from measured $\mathrm{Ar}$ I 810 and $751 \mathrm{~nm}$ fractional absorption line intensities as a function of sputter power for (a) $30 \mathrm{mTorr}, 1000 \mathrm{~W}$ rf, (b) $30 \mathrm{mTorr}, 2000 \mathrm{~W}$ rf, (c) $10 \mathrm{mTorr}, 1000 \mathrm{~W}$ rf, and (d) $10 \mathrm{mTorr}, 2000 \mathrm{~W}$ rf. 

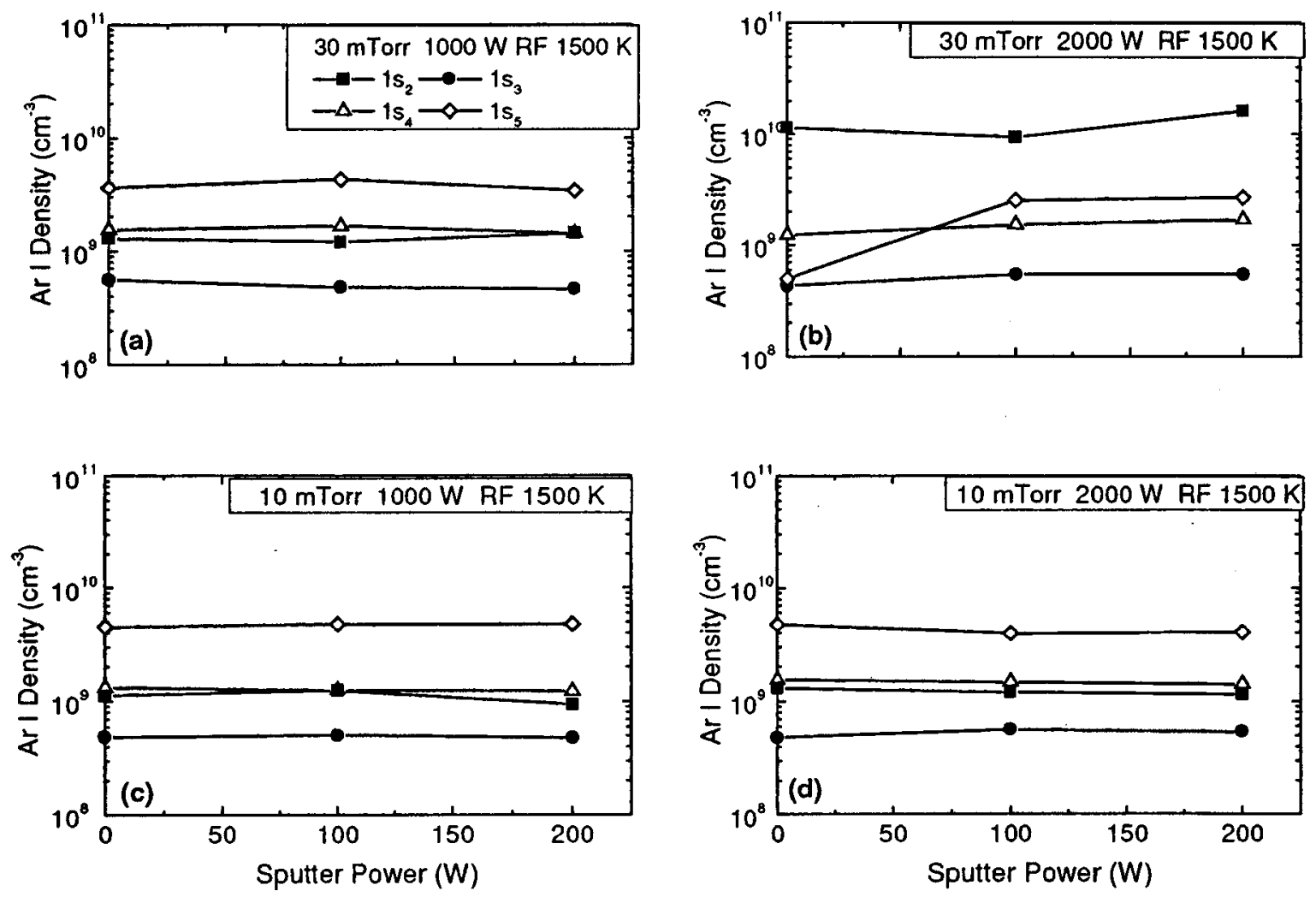

FIG. 14. Relative concentrations of the $1 s_{2}, 1 s_{3}, 1 s_{4}$, and $1 s_{5}$ levels comprising the $4 s$ excited state in $\operatorname{Ar} \mathrm{I}$ at an assumed temperature of $1500 \mathrm{~K}$ as a function of sputter power for (a) $30 \mathrm{mTorr}, 1000 \mathrm{~W}$ rf, (b) $30 \mathrm{mTorr}, 2000 \mathrm{~W}$ rf, (c) $10 \mathrm{mTorr}, 1000 \mathrm{~W}$ rf, and (d) $10 \mathrm{mTorr}, 2000 \mathrm{~W}$ rf.

$1 s_{3}$ at all three assumed temperatures. A similar ordering is observed at $30 \mathrm{mT}$ Torr and $1000 \mathrm{~W}$ rf. However, at $30 \mathrm{mTorr}$ and $2000 \mathrm{~W}$ rf the level ordering changes to $1 s_{2}, 1 s_{4}, 1 s_{5}$, and $1 s_{3}$ at $0 \mathrm{~W}$ sputter power and $1 s_{2}, 1 s_{5}, 1 s_{4}$, and $1 s_{3}$ at 100 and $200 \mathrm{~W}$ sputter power.

Based solely on the excitation threshold energies for the sublevels $\left(11.548 \mathrm{eV}\right.$ for $1 s_{5}, 11.62 \mathrm{eV}$ for $1 s_{4}, 11.723 \mathrm{eV}$ for $1 s_{3}$, and $11.828 \mathrm{eV}$ for $1 s_{2}$ ) we expect the ordering to be $1 s_{5}, 1 s_{4}, 1 s_{3}$, and $1 s_{2}$. However, in all cases the densities of both the $1 s_{4}$ and $1 s_{2}$ resonance energy levels are greater than the $1 s_{3}$ metastable level. This may be a result of the additional population mechanism, radiation trapping, of the resonance levels. This effect is more apparent at the higher pressure of 30 mTorr when the resonance state $1 s_{2}$ is observed to have a concentration higher than both metastable states at $2000 \mathrm{~W}$ rf power. Such a result is consistent with radiation trapping of the ground state $\left(1 s_{4}-1 p_{0}\right)$ and $\left(1 s_{2}-1 p_{0}\right)$ transitions, although higher electron densities associated with increased pressures are also expected to contribute. Similar excited level ArI ordering, $1 s_{5}, 1 s_{4}, 1 s_{2}$, and $1 s_{3}$ has also been reported by Hebner et al. ${ }^{16}$ for an inductively coupled argon plasma with a pressure range of 5-50 mTorr.

Finally, most models of argon discharges calculate a lumped value for the concentrations in the ArI $4 s$ manifold, for example see Refs. 1 and 17. Therefore, the sublevel densities have been added together and are plotted as a function of sputter power for 10 and 30 mTorr pressure, 1000 and $2000 \mathrm{~W}$ rf power, and an assumed temperature of $1500 \mathrm{~K}$, in Fig. 15. The largest value in excited level argon, Ar*, con- centration is observed at 30 mTorr and $2000 \mathrm{~W}$ rf with a value of $1.4 \times 10^{10} \mathrm{~cm}^{-3}$ at $0 \mathrm{~W}$ sputter power and 2.1 $\times 10^{10} \mathrm{~cm}^{-3}$ at $200 \mathrm{~W}$ sputter power. This observation is a result of the largest value in the $1 s_{2}$ resonant state density under these specific conditions as shown in Fig. 14. As mentioned above, this density maximum may be attributed to increased ground state transition radiation trapping and also, a maximum electron density for the experimental conditions studied.

\section{CONCLUSIONS}

An optical absorption spectroscopy (OAS) method has been used to measure absolute, average concentrations of

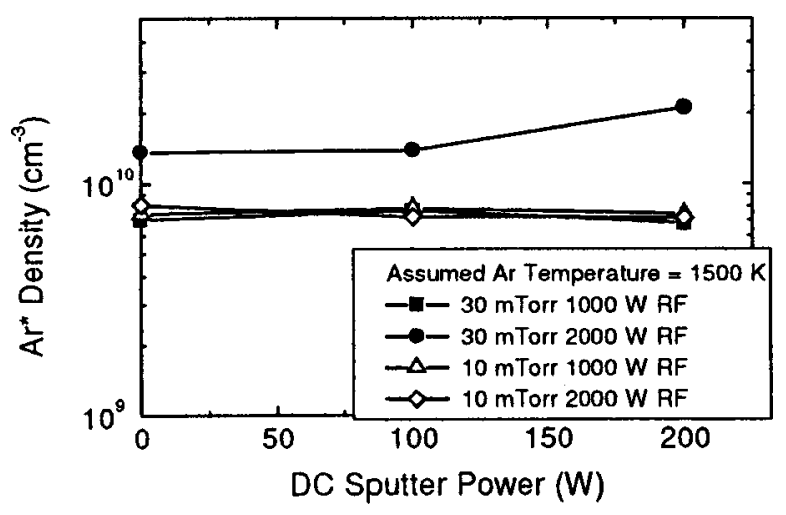

FIG. 15. Power and pressure dependence of the summed concentration of the excited state $4 s$ manifold, Ar*, in argon. 
long lived, gas phase species in IPVD discharges. The results have been obtained by coupling the OAS measurement technique with the curve of growth analysis method. The absolute, average gas phase densities of copper ground and metastable states along with neutral argon metastable and resonance states have been presented as a function of argon pressure, and power supplied to the discharge.

It is difficult to compare values of concentrations under different experimental conditions without an independent measurement of gas phase neutral copper and argon temperature. The derived values of neutral copper, metastable state densities (which do not have a temperature dependence) were found to increase with dc sputter power and neutral argon pressure and show no clear variation with rf power. Comparison of neutral copper densities derived from the OAS absorption fractions and QCM measurements of flux indicate thermalization temperatures of greater than $1300 \mathrm{~K}$ in the vicinity of the wafer chuck. This very useful result allows a more informed comparison of the neutral copper, metastable, and ground state densities. At such temperatures, the two populations are comparable at 30 mTorr, $200 \mathrm{~W}$ sputter power and $1000 \mathrm{~W}$ rf ICP power and also at 10 mTorr, $100 \mathrm{~W}$ sputter power and $1000 \mathrm{~W}$ rf ICP power with concentrations of the order $10^{10} \mathrm{~cm}^{-3}$. This result also emphasizes the need for independent measurement of gas phase copper temperature.

Neither the argon metastable $\left(1 s_{3}\right.$ and $\left.1 s_{5}\right)$ or resonance $\left(1 s_{2}\right.$ and $\left.1 s_{4}\right)$ state densities show clear trends with changes in any of the variable experimental parameters. This result is attributed to changes in population balance of the argon atom, metastable and resonance states with varying experimental conditions. The experimentally observed ordering of level concentrations at $10 \mathrm{mTorr}$ and at $30 \mathrm{mTorr}$ and 1000 $\mathrm{W} \mathrm{rf}$ is $1 s_{5}, 1 s_{4}, 1 s_{2}$, and $1 s_{3}$ at all three assumed temperatures. At $30 \mathrm{mTorr}$ and $2000 \mathrm{~W}$ rf the level ordering changes to $1 s_{2}, 1 s_{4}, 1 s_{5}$, and $1 s_{3}$ at $0 \mathrm{~W}$ sputter power and $1 s_{2}, 1 s_{5}, 1 s_{4}$, and $1 s_{3}$ at 100 and $200 \mathrm{~W}$ sputter power. The largest value in Ar* concentration is found at $30 \mathrm{mTorr}$ and $2000 \mathrm{~W}$ rf as a result of a corresponding maximum in the $1 s_{2}$ resonance state density under these specific conditions.

These results are essential for implementing accurate computational simulations of discharges under similar conditions. The long lifetimes of metastable states mean that they play a significant role in the power balance and ionization balance of IPVD discharges when their concentrations are sufficiently high. The comparison of the copper densities with those derived from QCM results has also given a very useful indication of neutral copper temperatures in the vicinity of the substrate stage.

\section{ACKNOWLEDGMENTS}

The authors would like to thank J. E. Lawler, J. J. Curry, and R. C. Woods for helpful discussions, G. A. Hebner for a critical reading of the manuscript, and Motorola Inc. for financial support.

\section{APPENDIX A: CURVE OF GROWTH METHOD FOR HYPERFINE STRUCTURE}

The frequency position of each hyperfine component is described by an offset from an arbitrary reference frequency, chosen to be the position of the $324.754 \mathrm{~nm}$ line. The offset is calculated in units of the Doppler width, in a manner similar to the definitions of $\xi$ and $y$ in Eq. (6). The full form, including hyperfine components, of the integral in Eq. (2) for a Voigt profile is

$$
\frac{W}{b_{D}}=\frac{1}{\sqrt{\ln 2}} \int_{-\infty}^{+\infty} d \xi\left[1-e^{-\Sigma_{j=1}^{12} \alpha_{j} \frac{P^{\prime} X s}{\pi} \int_{-\infty}^{+\infty} d y\left[\frac{e^{-y^{2}}}{a^{2}+\left(\xi-\Delta_{j}-y\right)^{2}}\right]}\right],
$$

where

$$
\begin{aligned}
& \sum_{j=1}^{12} \alpha_{j}=1, \\
& \Delta_{j}=\frac{v_{j}-v_{0}}{b_{D}} \sqrt{\ln 2 .}
\end{aligned}
$$

$v_{0}$ is the reference frequency $(\mathrm{Hz}), \alpha_{j}$ is the normalized line strength fraction due to $j$ th hyperfine line (dimensionless), $\Delta_{j}$ is the position offset of $j$ th hyperfine line (dimensionless), and the other symbols are the same as in Eq. (6). Note that the offset, being in units of the Doppler width, is a function of temperature. Due to the increased computational complexity introduced by the temperature dependent offsets, results are reported at only three assumed temperatures, 350, 500, and $1500 \mathrm{~K}$. The effect of the hyperfine structure on the curves of growth is to make the multiline curve for a given $a$ value remain linear for higher $P^{\prime} X$ values than the single line curve of growth.

Our Mathematica ${ }^{\circledR}$ program finds the value of $P^{\prime} X$ that satisfies Eq. (A1) for a given value of the ratio between the equivalent width and the Doppler width at a particular temperature. The volume density (reported in $\mathrm{cm}^{-3}$ ) is obtained from the definition of $P^{\prime}$ in Eq. (4), and using the experimental absorption path length of $0.46 \mathrm{~m}$.

\section{APPENDIX B: PARAMETERS AND NOTES ON PARTICULAR ATOMS}

\section{Ground state copper}

The frequency and Einstein $A_{u \rightarrow 1}$ coefficient for the ground state copper line $\lambda_{0}=324.754 \mathrm{~nm}$ were obtained from Ref. 18: $A_{u \rightarrow 1}=1.39 \times 10^{8} \mathrm{~s}^{-1}, g_{\text {up }}=4, g_{\text {lo }}=2$. The pressure broadening linewidth of $90 \mathrm{MHz} / \mathrm{Torr}$ (HWHM) was obtained from Ref. 18.

\section{Metastable copper}

The measured $W / b_{D}$ ratios for the density of metastable copper atoms were small enough to use the approximation of Eq. (11) to obtain densities. In addition, the hyperfine structure of this state contains 18 lines, causing the curve of growth to remain linear for even higher values of $P^{\prime} X$ than for the ground state case. The frequency and Einstein $A_{u \rightarrow 1}$ 
TABLE II. Einstein $A_{u \rightarrow 1}$ coefficients for excited state argon lines.

\begin{tabular}{ccccccc}
\hline \hline $\begin{array}{c}\text { Wavelength } \\
(\mathrm{nm})\end{array}$ & $\begin{array}{c}\text { Lower } \\
\text { level }\end{array}$ & $\begin{array}{c}\text { Metastable/ } \\
\text { resonance }\end{array}$ & $\begin{array}{c}\text { Upper } \\
\text { level }\end{array}$ & $\begin{array}{c}A \\
\times 10^{6} \mathrm{~s}^{-1}\end{array}$ & $g_{\text {lo }}$ & $g_{\text {up }}$ \\
\hline 706.722 & $1 s_{5}$ & metastable & $2 p_{3}$ & 3.80 & 5 & 5 \\
750.384 & $1 s_{2}$ & resonance & $2 p_{1}$ & 44.5 & 3 & 1 \\
751.465 & $1 s_{4}$ & resonance & $2 p_{5}$ & 40.2 & 3 & 1 \\
794.818 & $1 s_{3}$ & metastable & $2 p_{4}$ & 18.6 & 1 & 3 \\
810.369 & $1 s_{4}$ & resonance & $2 p_{7}$ & 25.0 & 3 & 3 \\
811.531 & $1 s_{5}$ & metastable & $2 p_{9}$ & 33.1 & 5 & 7 \\
\hline \hline
\end{tabular}

coefficient for the metastable state copper line $\lambda_{0}$ $=510.5541 \mathrm{~nm}$ were also obtained from Ref. 19: $A_{u \rightarrow 1}$ $=0.020 \times 10^{8} \mathrm{~s}^{-1}, g_{\text {up }}=4, g_{\text {lo }}=6$.

\section{Excited state argon atoms}

Argon has only one significant isotope, ${ }_{18} \mathrm{Ar}^{40}$ (99.60\%), and no hyperfine structure $(I=0)$. The first four lowest excited states are the $1 s_{2}, 1 s_{3}, 1 s_{4}$, and $1 s_{5}$ levels of the $4 s$ manifold. The $1 s_{3}$ and $1 s_{5}$ levels are true metastable levels, they are not radiatively coupled to the ground state. The $1 s_{2}$ and $1 s_{4}$ resonance levels are not metastable states, but have long effective lifetimes due to strong trapping of their spectroscopic line emission.

Six neutral argon spectroscopic lines were used to obtain the excited level densities and are listed in Table II along with the lower level from which they originate. The lines that originate from the same lower level should ideally yield the same density results, and the difference between those results

TABLE III. Lifetimes of excited states argon levels.

\begin{tabular}{ccc}
\hline \hline Level & Pressure (mTorr) & Lifetime (ns) \\
\hline $1 s_{2}$ & $\ldots$ & 0.24 \\
$1 s_{3}$ & 10 & 30000 \\
$1 s_{3}$ & 30 & 200000 \\
$1 s_{4}$ & $\ldots$ & 10 \\
$1 s_{5}$ & 10 & 30000 \\
$1 s_{5}$ & 30 & 200000 \\
\hline \hline
\end{tabular}

provides a measure of the uncertainty in the measurements. The Einstein $A_{u \rightarrow 1}$ coefficients for all argon lines were obtained from Ref. 20 and are also listed in Table II.
The pressure broadening coefficient for the $811.531 \mathrm{~nm}$ line was obtained from Ref. 21. The pressure broadening coefficients for all other ArI lines were obtained from Ref. 22.

The lifetimes of the excited states of interest used are given in Table III. The lower state lifetimes of the metastable states $1 s_{3}$ and $1 s_{5}$ are functions of pressure and were obtained by extrapolating data found in Figs. 10 and 13 of Ref. 23. The resulting lifetimes are approximate, but are expected to be sufficiently accurate for the purposes of this study. The lifetimes of the resonance levels $1 s_{2}$ and $1 s_{4}$ were also obtained from Ref. 23.

${ }^{1}$ J. Lu and M. Kushner, J. Vac. Sci. Technol. A (submitted).

${ }^{2}$ P. L. G. Ventzek, S. Rauf, D. G. Coronell, V. Arunachalam, X.-Y. Liu, J. Arnold, D. Denning, S. Garcia, A. Korkin, and Y.-K. Kim, "IMP-PVD equipment level process analysis using simulation," presented at the 46th AVS International Symposium, Seattle (1999).

${ }^{3}$ Y. Andrew, J. H. Booske, S. Lu, T. G. Snodgrass, and A. E. Wendt, J. Vac. Sci. Technol. A (submitted).

${ }^{4}$ R. C. Walmsley, K. Mitsuhashi, and J. E. Lawler, Rev. Sci. Instrum. 64, 45 (1993)

${ }^{5}$ T. G. Snodgrass, J. H. Booske, W. Wang, A. E. Wendt, and J. L. Shohet, Rev. Sci. Instrum. 70, 1525 (1999).

${ }^{6}$ A. Thorne, U. Litzen, and S. Johansson, Spectrophysics (Springer, New York, 1999).

${ }^{7}$ I. C. Abraham, Ph.D. Thesis, University of Wisconsin-Madison, 1999.

${ }^{8}$ S. S. Penner, Quantitative Molecular Spectroscopy and Gas Emissivities (Addison-Wesley, Reading, MA, 1959).

${ }^{9}$ P. A. Jansson and C. L. Korb, J. Quant. Spectrosc. Radiat. Transf. 8, 1399 (1968).

${ }^{10}$ C. L. Korb, R. H. Hunt, and E. K. Plyler, J. Chem. Phys. 48, 4252 (1968).

${ }^{11}$ F. G. Lether and P. R. Wenston, J. Comput. Appl. Math. 34, 75 (1991).

${ }^{12}$ H. Kopfermann, Nuclear Moments (Academic, New York, 1958).

${ }^{13}$ G. Hermann, G. Lasnitschka, C. Schwabe, and D. Spengler, Spectrochim. Acta B 48, 1259 (1993).

${ }^{14}$ Y. Andrew, J. Booske, T. G. Snodgrass, and A. E. Wendt, Plasma Sources Sci. Technol. (submitted).

${ }^{15}$ W. Dickson, Ph.D. Thesis, University of Strathclyde, 1993.

${ }^{16}$ G. Hebner et al., J. Appl. Phys. 80, 2624 (1996).

${ }^{17}$ M. J. Grapperhaus, Z. Krivokapic, and M. J. Kushner, J. Appl. Phys. 83, 35 (1998).

${ }^{18}$ K. Fu, M. Jogwich, M. Knebel, and K. Wiesemann, At. Data Nucl. Data Tables 61, 10 (1995).

${ }^{19}$ C. J. Chen, Phys. Rev. A 18, 2192 (1978).

${ }^{20}$ W. L. Wiese, J. W. Brault, K. Danzmann, V. Helbig, and M. Kock, Phys. Rev. A 39, 2461 (1989).

${ }^{21}$ C. S. Lee, D. M. Camm, and G. H. Copley, J. Quant. Spectrosc. Radiat. Transf. 15, 211 (1975).

${ }^{22}$ G. H. Copley and D. M. Camm, J. Quant. Spectrosc. Radiat. Transf. 14, 899 (1974).

${ }^{23}$ E. Ellis and N. D. Twiddy, J. Phys. B 2, 1366 (1969). 